\title{
Functionalization of Carboxylated Multiwall Nanotubes with Dapsone Derivatives and Study of their Antibacterial Activities against $E$. coli and S. aureus
}

\author{
JAVAD AZIZIAN ${ }^{1 *}$, MALAK HEKMATI ${ }^{1}$ and ORKIDEH GHORBAN DADRAS ${ }^{2}$ \\ 1Department of Chemistry, Science and Research branch, Islamic Azad University, Tehran, Iran. \\ ${ }^{2}$ Department of Medicinal Chemistry, Pharmaceutical Sciences Branch, Islamic Azad University \\ (IAUPS), Tehran, Iran. \\ ${ }^{*}$ Corresponding author E-mail: Azizian@ @rbiau.ac.ir \\ http://dx.doi.org/10.13005/ojc/300236
}

(Received: April 15, 2014; Accepted: May 22, 2014)

\begin{abstract}
Bacteria are becoming resistant to the antibiotics prescribed and therefore new treatments are essential to be developed. Multiwall carbon nanotubes (MWNTs) have interesting antibacterial activities and offering a promising new treatment preventing bacteria from becoming resistant. With this aim, we report for the first time three novel modified carboxylated multiwall carbon nanotubes consisting of MWNT-Dapsone, MWNT-Dapsone-imine and MWNT-Dapsone-imine. Copper complex. The functionalized carboxylated multiwall nanotubes were then characterized by FT-IR, Raman, TEM. Moreover, the antibacterial activity of the MWNT-COOH (A), MWNTdapsone (B), MWNT-Dapsone-imine (C) MWNT-Dapsoneimine.Copper complex (D), Dapsone (E(, Dapsone-imine $(F)$, has been investigated against gram-negative Escherichia coli and grampositive Staphylococcus aureus. These results show that compund $\mathrm{F}$ exhibited significant antibacterial activity and have a potential to be used as antibacterial agent.
\end{abstract}

Key words: Carboxylated multiwall nanotubes, Dapsone, Functionalization, Characterization, Antibacterial activity.

\section{INTRODUCTION}

Antimicrobial resistance is fast becoming a major problem with rapid increases in multidrugresistant bacteria (Saha et al., 2009). In general, bacteria have the genetic ability to send and acquire resistance to drugs, which are used as pharmacologic agents (Faúndez et al., 2004). The microbial resistance represent a global concern and the outlook for the use of antimicrobial drugs in the future is still uncertain (Stanila et al., 2011; Chaudhary et al., 2010).

Recently, carbon nanotubes (CNTs) have attracted increasing attention in biomedical fields due to their unique structure and properties, including high aspect ratios, large surface areas, nanosized stability and rich surface chemical 
functionalities (Wu et al., 2011; Azizian et al., 2013). With these unique structures and properties, CNTs have been developed as promising nanoplatforms to immobilize biological or therapeutic molecules, such as proteins, antibodies, siRNA or drugs on their surface, and especially these functionalized CNTs are capable of crossing biological barriers independently of the cell type, which makes them suitable candidates for drug delivery systems. (Tian et al., 2011; Hu et al., 2009; Holzinger., 2001). The chemical modification of carbon nanotubes has received significant attention in recent decades (Chen et al., 1998; Hamon et al., 1999). Chemical functionalization is a common technique to increase dispersion stability and biocompatibility of CNTs (Georgakilas et al., 2002; Sun et al., 2002).

CNT have been proposed as multipurpose innovative transporters for drug delivery since they can be covalently or non-covalently attached to drug molecules and carry them throughout the body in a biocompatible way (Karchemski et al., 2012; Entezari et al., 2013). Modified carbon nanotubes have been widely studied for their antibacterial, antifungal and potential cytotoxic chemotherapeutic agents. Many factors may influence the antibacterial activity of carbon nano materials, including: electronic structure, size and surface chemical properties, as well as the interacting conditions between carbon nanomaterials and bacterial cells.(Liu et al., 2012). More recently, transition metal complexes have attracted attentions of inorganic, metallo-organic as well as bio-inorganic chemists because of their structural diversity, antibacterial activity and enormous number of biological applications (Safari et al., 2013; Yousefi et al., 2012). The ability of metal to combine with ligands and then release ligand in specific process make them ideal candidate for use in biological system. It is well known that synthetic copper(II) complexes have been reported to act as potential anticancer and antibacterial agents (Tella and Obaleye, 2009). The pharmacological activities of these metal complexes depend on the metal ion, organic ligands and the structure of the compounds (Yousefi et al., 2014). Dapsone ((4, 4'-diaminodiphenylsulphone), a sulphone analog, is the main antileprosy drug because of its inherent level of bactericidal activity, easy application and minimal side effects (Makarov et al ., 2006; Wadher et al., 2009). As an extension of this research field, we aimed to attach the new pharmacologic agents to the surface of carboxylated multiwall nanotubes, in order to take advantage of the MWNT's outstanding biological properties and to screen the final products for their antibacterial activity.

\section{RESULT AND DISCUSSION}

\section{Infrared spectroscopy}

FT-IR spectroscopy was used to identify the chemical groups that were attached to MWNTs. Figure 1 shows the FT-IR spectra of MWNT-COOH (A), MWNT-dapsone (B), MWNT-Dapsone-imine (C) MWNT-Dapsoneimine.Copper complex (D).

In spectrum (a), the band at around 1568 $\mathrm{cm}^{-1}$ corresponds to the stretching mode of the $\mathrm{C}=\mathrm{C}$ double bond that forms the framework of the carbon nanotube sidewall. The peaks at 1705 and 2450 $\mathrm{cm}^{-1}$ to $3400 \mathrm{~cm}^{-1}$ apparently corresponds to the stretching modes of the carboxylic acid groups. The two bands at around $2850 \mathrm{~cm}^{-1}$ which are seen in all spectrums are attributed to the $\mathrm{CH}$ stretching of MWNT-COOH defects. In spectrum (b), the three bands at $3143 \mathrm{~cm}^{-1}, 3304 \mathrm{~cm}^{-1}$ and $3381 \mathrm{~cm}^{-1}$ can

Table 1. Antibacterial screening data of Compound A-E against the tested bacteria (inhibition zone in $\mathrm{mm}$ )

\begin{tabular}{lccc}
\hline Compound & Concentration & E. coli & S. aureus \\
\hline Compound (A) & $1000 \mathrm{ppm}$ & 8 & 0 \\
Compound (B) & $1000 \mathrm{ppm}$ & 14 & 10 \\
Compound (C) & $1000 \mathrm{ppm}$ & 12 & 15 \\
Compound (D) & $1000 \mathrm{ppm}$ & 16 & 8 \\
Compound (E) & $1000 \mathrm{ppm}$ & 42 & 22 \\
Compound (F) & $1000 \mathrm{ppm}$ & 12 & 10 \\
\hline
\end{tabular}




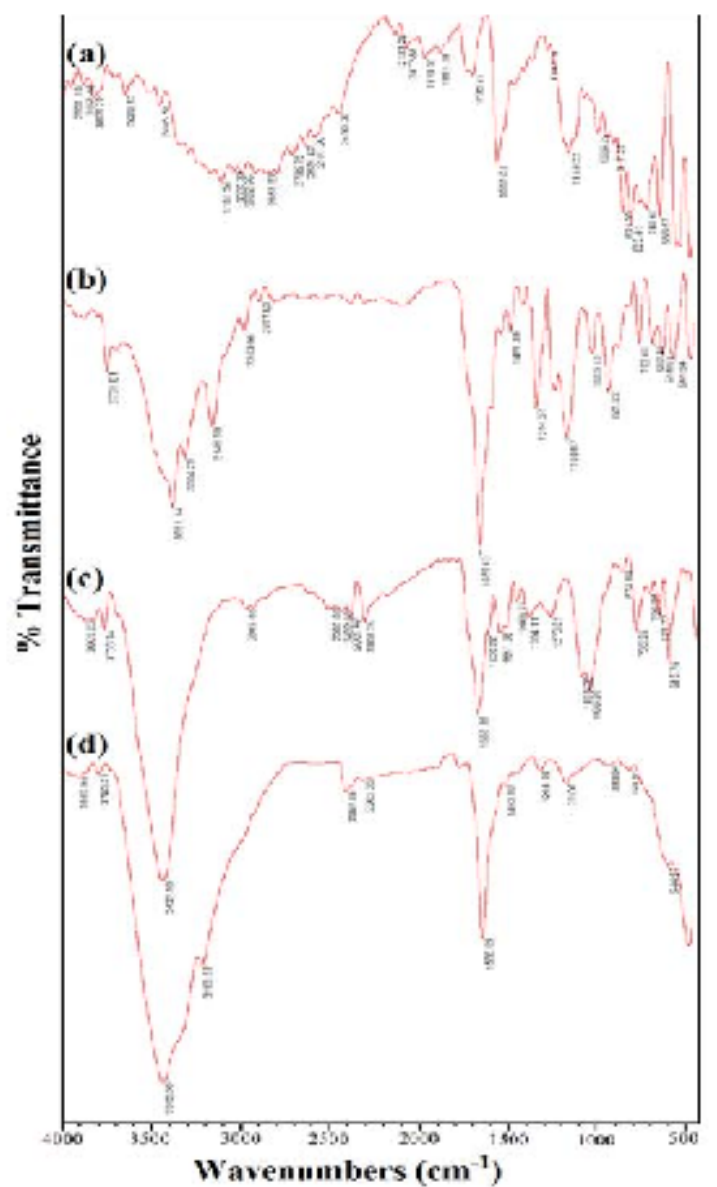

be assigned to the $\mathrm{N}-\mathrm{H}$ stretching modes and carbonyl peak in the spectrum (b) shift to $1656 \mathrm{~cm}^{-1}$ (as compared with $1705 \mathrm{~cm}^{-1}$ in spectrum (a)) is a result of amide $(\mathrm{C}=\mathrm{O}) \mathrm{NH}$ linkage formation. This could indicate that amidation reactions occurred between the amino groups of dapsone and the carboxyl groups on the surfaces of the MWNTs. In the spectrum (c) the new strong peak at $3429 \mathrm{~cm}^{-1}$ can be assigned to the O-H stretching modes. The carbonyl peak in the spectrum (c) shift to $1660 \mathrm{~cm}$ ${ }^{1}$ (as compared with $1705 \mathrm{~cm}^{-1}$ in spectrum (a)) is a result of amide $(\mathrm{C}=\mathrm{O}) \mathrm{NH}$ linkage formation and so the formation of a new peak in $1625 \mathrm{~cm}^{-1}$ indicating the presence of $\mathrm{C}=\mathrm{N}$ double bond This is certainly an indication for the formation of 2-((4-)(4aminophenylsulfonyl)phenylimino)methyl)phenol on the surfaces of the MWNTs.

In spectrum (d), the broad band at around $1588 \mathrm{~cm}^{-1}$ corresponds to the stretching mode of the $(C=O)$. The peak at $1625 \mathrm{~cm}^{-1}$ presents in compound $(C)$ was shifted to lower frequency of $1463 \mathrm{~cm}^{-1}$ in compound (D), respectively, thus indicating coordination of the metal ion to $\mathrm{N}$ atom. Furthermore, the nature of the metal-ligand bonding is confirmed by the newly formed bands at $\sim 543$ $\mathrm{cm}^{-1}$ in the spectra of this compound, which is tentatively assigned to $\mathrm{Cu}-\mathrm{O}$ vibration.

Fig. 1: FT-IR spectra of MWNT-COOH (A) and functionalized MWNTs (B-D)
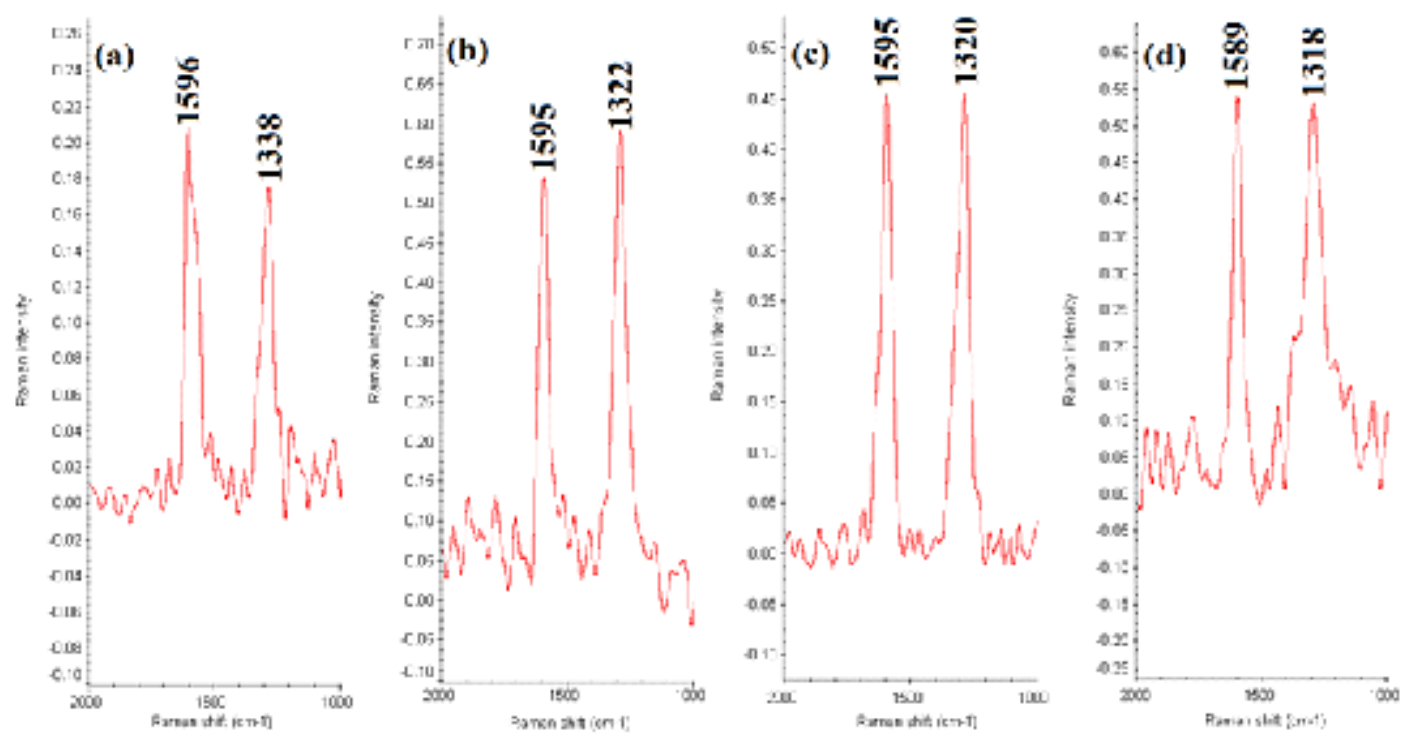

Fig. 2: Raman spectra of MWNT-COOH (A) and functionalized MWNTs (B-D) 


\section{Raman Spectroscopy}

Raman spectra offer useful information concerning the slightly structural changes of MWNTs, especially the changes owing to significant sidewall modification. As can be seen in Figure 2, the characteristic peaks of MWNT tangential modes, namely the $D$ band at around $1320 \mathrm{~cm}^{-1}$ and the $G$ band at around $1590 \mathrm{~cm}^{-1}$ slightly changed. We observed an increase in the ratio of intensities $R=$ ID/IG in modified nanotubes. This indicates an increased disorder of the graphitic structure of the modified nanotubes, which shows that the nanotubes were covalently modified ( Dresselhaus et al., 2005).

\section{TEM Characterization of the modified MWNTs}

Figure 3 presents TEM images of the MWNT-COOH (A) and the modified MWNTs (B-D). The MWNT-COOH show almost smooth surface (a) while increased roughness of the functionalized CNT surfaces evident in TEM images of MWNTCompounds.

\section{Biological studies \\ Antibacterial activity}

The antibacterial activity of MWNT-COOH

(A) as well as corresponding functionalized MWNTs (B-D) and compound $E$ and $F$ was performed against one Gram positive (Staphylococcus aureus) and another Gram negative (Escherichia coli) bacteria, and the results are summarized in Table 1. The results indicates that the modified MWNTs show higher activity than MWNT-COOH against these two bacteria (Fig 4). These data also demonstrate that MWNT-COOH has no activity on the growth of $S$. aureus bacteria. Compound $\mathrm{E}$ possessed a significant inhibitory effect against all the tested bacteria. The increase of the zone of inhibition for compound $\mathrm{C}$ when compared with corresponding ligands ( compound $\mathrm{F}$ ) is an indication that the modified MWNTs is able to decrease the population of Staphylococcus aureus bacteria. Moreover, Compounds (D) present higher activity than other functionalized MWNTs against $E$. coli. Therefore, it should be noted that presence of metal ion in the structure of compound D had a great influence on

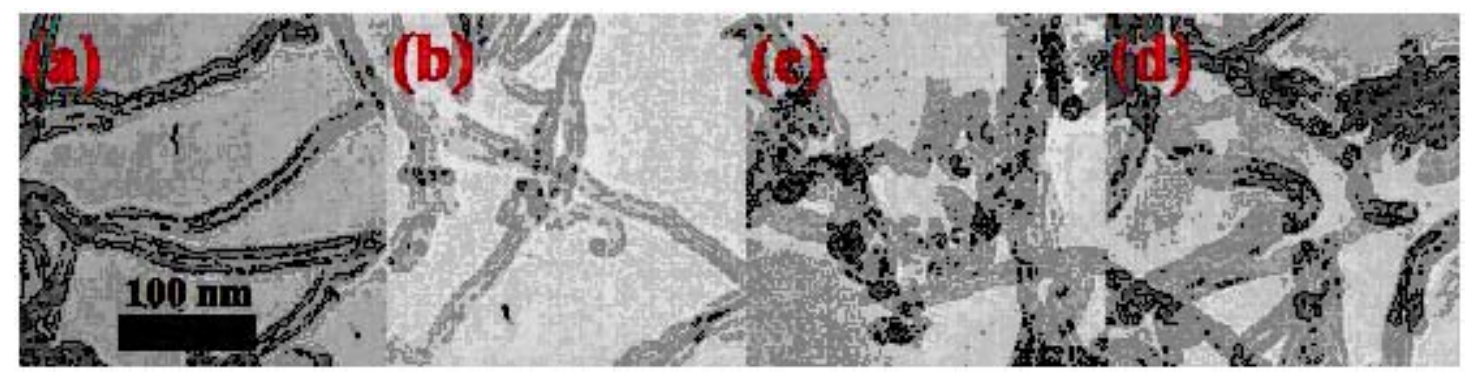

Fig. 3.: Transmission electron microscopy (TEM) of MWNT-COOH (A) and functionalized MWNTs (B-D)
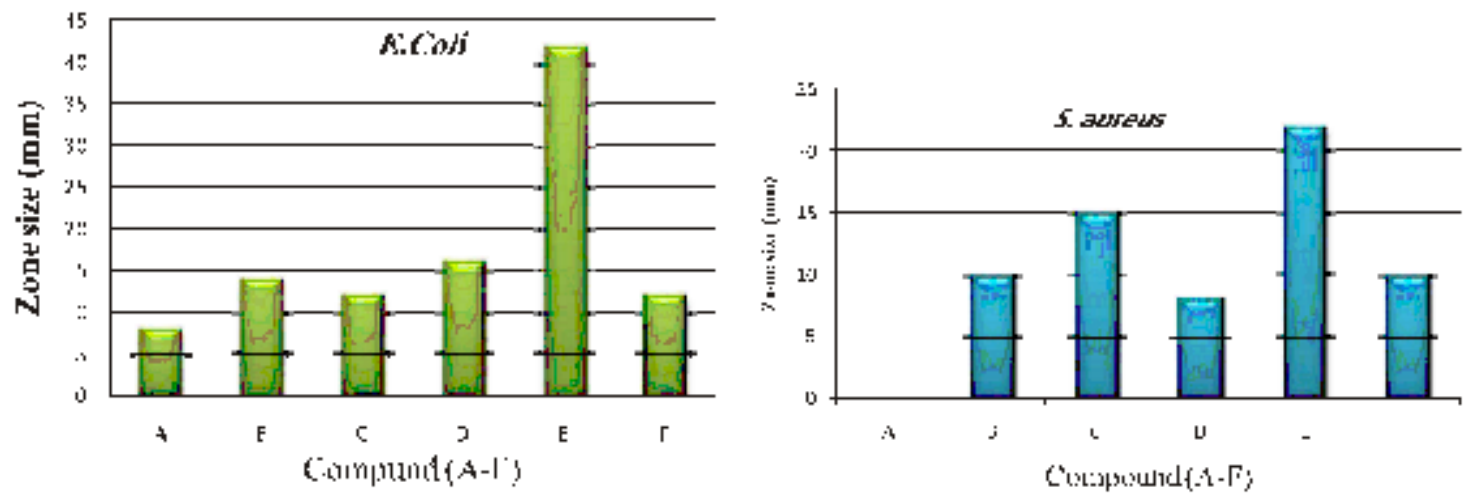

Fig. 4: Average diameter of zones of inhibition for compound (A-F) against E.coli and S. aureus bacteria 


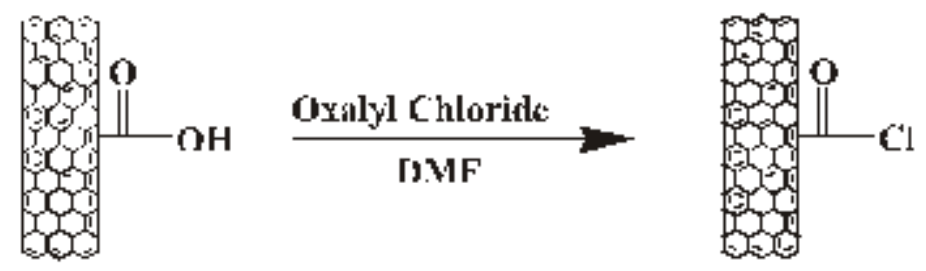

Fig. 5: Preparation of MWNT-COCI

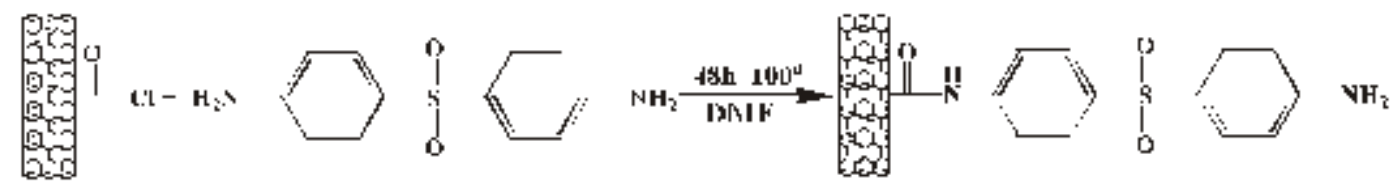

Fig. 6: Preparation of MWNT-D

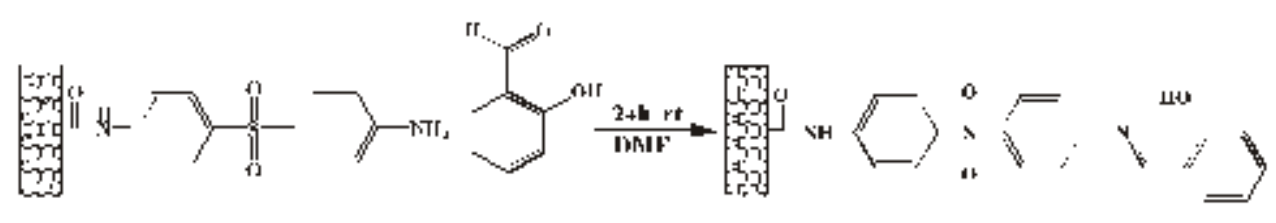

Fig. 7: Preparation of MWNT-DS

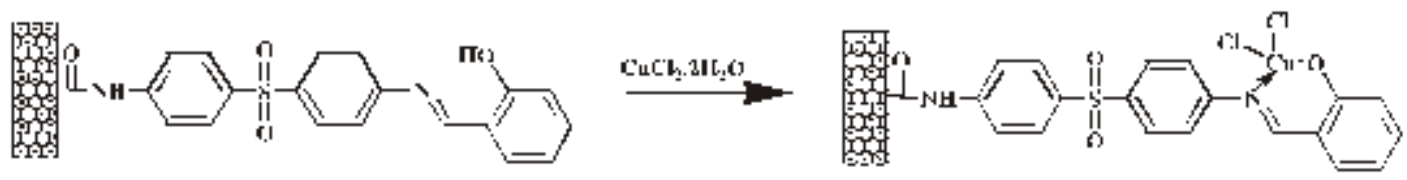

Fig. 8: Preparation of MWNT-DSC

the suppression activity of this compound on E.coli. Noticeably, The antibacterial activity of the compounds $\mathrm{F}$ and $\mathrm{C}$ against $E$.coli were in a similar range. An improved activity was observed for the functionalized MWNTs of the present investigation. As these results are preliminary, further study on the antibacterial activity of these complexes is highly recommended.

\section{EXPERIMENTAL}

\section{Material and methods}

All chemicals and reagents were purchased from Merck and used without further purification. MWNT- $\mathrm{COOH}$ (95\% purity, 20-30 nm; Netrino Co. Ltd) were purchased and used as received. The FT-IR spectra were recorded on a Nexus 870 FT-IR spectrometer using $\mathrm{KBr}$ pellets (Thermo Nicolet, Madison, WI). FT-Raman spectra were recorded on 960 ES spectrometer (Thermo Nicolet). TEM measurement was carried out on the LEO 912 AB electron microscope.

\section{Preparation of MWNT-COCI}

$60 \mathrm{mg}$ of the MWNT-COOH were sonicated in $90 \mathrm{ml}$ of DMF for 40 min to give a suspension. Oxaly- chloride $(2.5 \mathrm{ml})$ was added drop-wise to the MWNT suspension at $0^{\circ} \mathrm{C}$ under $\mathrm{N}_{2}$. The mixture was stirred at $0^{\circ} \mathrm{C}$ for $2 \mathrm{~h}$ and then at room temperature for another $2 \mathrm{~h}$. Finally, the temperature was raised to $70{ }^{\circ} \mathrm{C}$ and the mixture was stirred overnight to remove excess oxalyl chloride (Figure 5). After cooling to room temperature, the mixture was filtered through $0.2 \mu \mathrm{m}$ pore size polytetrafluoroethylene membrane. The filtrate was washed with $\mathrm{EtOH}\left(3^{*} 100 \mathrm{ml}\right)$, and then dried in an oven for $4 \mathrm{~h}$ at $60^{\circ} \mathrm{C}$. 
Preparation of MWNT-CO-4-(4-aminophenyl sulfonyl) benzenamine (MWNT-D)

$250 \mathrm{mg}$ of dapsone compound was sonicated in $90 \mathrm{ml}$ of DMF for $30 \mathrm{~min}$ and added to suspension $50 \mathrm{mg}$ MWNT-COCl, and the mixture was refluxed at $100{ }^{\circ} \mathrm{C}$ for $48 \mathrm{~h}$ (Figure 6). Then the mixture was cooling to room temperature and filtered through $0.2 \mu \mathrm{m}$ pore size polytetrafluoroethylene membrane. The filtrate was washed with $\mathrm{MeOH}\left(3^{*} 100 \mathrm{ml}\right)$ and THF $(100 \mathrm{ml})$. Subsequently, the black solid was vacuum dried at room temperature.

Preparation of MWNT-CO-2-((4-)(4aminophenylsulfonyl)phenylimino)methyl)phenol (MWNT-DS)

$250 \mathrm{mg}$ of dapsone compound sonicated in $90 \mathrm{ml}$ of DMF for $30 \mathrm{~min}$ and was added to suspension $50 \mathrm{mg} \mathrm{MWNT-COCl}$, and the mixture was refluxed at $100{ }^{\circ} \mathrm{C}$ for $48 \mathrm{~h}$. Then the mixture was cooling to room temperature. To the mixture cooled was added $300 \mathrm{mg}$ salicylaldehyde and then the mixture was stirred at room temperature for another $24 \mathrm{~h}$ (Figure 7). After completion of the reaction, the mixture was filtered and washed thoroughly with $\mathrm{MeOH}\left(3^{*} 100 \mathrm{ml}\right)$ and THF (100 $\mathrm{ml}$ ). Subsequently, the black solid was vacuum dried at room temperature.

Preparation of MWNT-CO-[2-((4-(4-amino phenylsulfonyl) phenylimino) methyl) phenol] [CuCl ${ }_{2}$ (MWNT-DSC)

$0.2 \mathrm{~g}$ of nano.dapsone.imin were sonicated in $30 \mathrm{ml}$ of $\mathrm{N}, \mathrm{N}$-dimethylformamide (DMF) for $30 \mathrm{~min}$. methanolic solution of $\mathrm{CuCl}_{2}$. $2 \mathrm{H} 2 \mathrm{O}(0.1 \mathrm{~g})$ was added dropwise to the suspension Nano.dapsone.imin (Fig 8). The mixture was sonicated for one hour and stirred at room temperature for $24 \mathrm{~h}$. Finally, the mixture was filtered and washed thoroughly with tetrahydrofuran. Subsequently, the black solid was vacuum-dried at room temperature for $5 \mathrm{~h}$.

\section{Biological studies}

All of the synthesized compounds were screened for their antibacterial activity against two strains of bacteria (Escherichia coli and Staphylococcus aureus ). The antibacterial activities of the ligand and metal complexes were carried out using well diffusion method. Muller Hilton Agar was prepared and sterilized. $20 \mathrm{ml}$ of media was poured into the petri-dishes and allowed to solidify. The wells were made carefully and these were completely filled with the test solutions. The test solutions of the studied compounds were prepared in DMF at a concentration of $1,000 \mu \mathrm{g} / \mathrm{mL}$. The plates were incubated immediately at $37^{\circ} \mathrm{C}$ for 24 hours and the diameter of the inhibiting area around each well was estimated, which is described as the inhibiting effect against bacteria. The average of three diameters was calculated for each sample.

\section{CONCLUSIONS}

In summary, we have introduced pharmacologic agents onto the surface of MWNTs in order to observe the effect of different substituents attached to the surface of MWNTs on the studied bacteria. The functionalized MWNTs have been characterized by FT-IR and Raman spectroscopies and TEM. The antibacterial activity of the synthesized compounds has been evaluated against E.coli and S. aureus. Functionalized MWNTs showed the ability to inhibit E.coli and S. aureus. The most outstanding results were obtained from the activity of Compound $F$ against E.coli, which exhibited much higher antibacterial activity than other modified MWNTs. Therefore, compund F seems to be a very promising candidate for further tests which will be carried out in the near future.

\section{ACKNOWLEDGMENTS}

The authors like to express their profound gratitude to the Research Council of Islamic Azad University Science and Research branch, Iran for providing necessary research facilities and financial assistance.

\section{REFERENCES}

1. Saha, S.; Dhanasekaran, D.; Chandraleka, S.; Panneerselvam, A. Facta univ. Ser. Phys.
Chem. Tech., 2009, 7, 73-80.

2. Faúndez, G.; Troncoso, M.; Navarrete, P.; 
Figueroa, G. BMC microbiol., 2004, 4, 19.

3. Stnil, A.; Braicu, C.; Stnil, S.; Pop, R. M. Not. Bot. Horti Agrobo., 2011, 39.

4. Chaudhary, M.; Pareek, D.; Ojha, K.; Pareek, A. Int. J. Curr. Chem., 2010, 1, 175-179.

5. Wu, H.; Liu, G.; Wang, X.; Zhang, J.; Chen, Y.; Shi, J.;Yang, H.; Hu, H.; Yang, S. Acta biomater., 2011, 7, 3496-3504.

6. Azizian, J.; Ardestani, E.; Entezari, M. Curr. Nanosci., 2013, 9, 442-446.

7. Tian, Z.; Shi, Y.; Yin, M.; Shen, H.; Jia, N. Nano Biomedicine \& Engineering, 2011, 3.

8. Hu, C. Y.; Xu, Y. J.; Duo, S. W.; Zhang, R. F.; Li, M. S. J. Chin. Chem. Soc., 2009, 56, 234-239.

9. Holzinger, M.; Vostrowsky, O.; Hirsch, A.; Hennrich, F.; Kappes, M.; Weiss, R.; Jellen, F. Angew. Chem. Int. Edit., 2001, 40, 4002-4005.

10. Chen, J.; Hamon, M. A.; Hu, H.; Chen, Y.; Rao, A. M.; Eklund, P. C.; Haddon, R. C. Science, 1998, 282, 95-98.

11. Hamon, M. A.; Chen, J.; Hu, H.; Chen, Y.; Itkis, M. E.; Rao, A. M.; Eklund, P. C.; Haddon, R. C. Adv. Mater., 1999, 11, 834-840.

12. Georgakilas, V.; Kordatos, K.; Prato, M.; Guldi, D. M.; Holzinger, M.; Hirsch, A. J. Am. Chem. Soc., 2002, 124, 760-761.

13. Sun, Y.-P.; Fu, K.; Lin, Y.; Huang, W. Accounts Chem. Res., 2002, 35, 1096-1104.
14. Karchemski, F.; Zucker, D.; Barenholz, Y.; Regev, O. J. Control. Release, 2012, 160, 339-345.

15. Entezari, M.; Safari, M.; Hekmati, M.; Hekmat, S.; Azin, A. Med. Chem. Res., 2014, 23, 487495.

16. Liu, S.; Hu, M.; Zeng, T. H.; Wu, R.; Jiang, R.; Wei, J.; Wang, L.; Kong, J.; Chen, Y. Langmuir, 2012, 28, 12364-12372.

17. Safari, M.; Yousefi, M.; Jenkins, H. A.; Torbati, M.; Amanzadeh, A. Med Chem Res.2013, doi:10.1007/s00044-013-0549-9.

18. Yousefi, M.; Safari, M.; Torbati, M. B.; Kazemiha, V. M.; Sanati, H.; Amanzadeh, A. Appl. Organomet. Chem., 2012, 26, 438

19. C Tella, A.; A Obaleye, J. Journal of Chemistry, 2009, 6, S311-S323.

20. Yousefi, M.; Safari, M.; Torbati, M.; Amanzadeh, A. J. Struc. Chem., 2014, 55, 101-106.

21. Makarov, V.; Riabova, O. B.; Yuschenko, A.; Urlyapova, N.; Daudova, A.; Zipfel, P. F.; Möllmann, U. Journal of Antimicrob. Chemoth., 2006, 57, 1134-1138.

22. Wadher, S.; Puranik, M.; Karande, N.; Yeole, P. International Journal of PharmTech Research, 2009, 1.

23. Dresselhaus, M. S.; Dresselhaus, G.; Saito, R.; Jorio, A. Phys. Rep., 2005, 409, 47-99. 